\title{
REFLEXÃO INICIAL PARA A PRODUÇÃO DE UMA EDIÇÃO CRÍTICA DA LÍRICA DE LUÍS DE CAMÕES
}

Marcello Moreira

UESB

\section{RESUMO:}

Objetiva-se aqui apresentar os procedimentos de pesquisa necessários para a fatura de uma edição crítica do corpus poético atribuído a Luís de Camões. Em artigo a ser em breve publicado, desenvolvemos os princípios aqui expostos e também as críticas ao método de Lachmann e aos seus ulteriores desenvolvimentos em Itália.

\section{PALAVRAS-CHAVE:}

Crítica textual; métodos filológicos; lachmannismo; edição crítica; Luís de Camões

\section{ABSTRACT:}

The aim of this paper is to present the procedures which must be carried out in order to achieve a critical edition of Luís de Camões' lyrical works. Soon a long paper on Luís de Camões lyrical works and a critical edition of one of his sonnets will be published, where it is intended to demonstrate the principles and procedures here only proposed.

\section{KEYWORDS:}

Textual criticism; philological methods; lachmanism; critical edition; Luís de Camões

(I)

Durante os últimos anos, vimos encetando uma reflexão sistemática sobre as relações entre campo historiográfico contemporâneo e teorias da edição, de que resultou o livro sobre a tradição atribuída a Gregório de Matos e Guerra e vários artigos e capítulos de livro, em que se criticam tanto o anacronismo de categorias operacionalizantes de métodos editoriais quando aplicadas à edição de textos de quaisquer tempos e lugares, sem observação de sua pertinência histórica - como, por exemplo, "genuinidade", "originalidade", "genialidade" e lectio difficilior -, quanto a dissociação entre prática editorial/ hermenêutica e pensamento historiográfico. O que segue são nótulas sobre os problemas que todo filólogo tem de arrostar quando se propõe pensar seu fazer como histórico e indissociável do campo historiográfico. É na verdade um bosquejo mínimo para introduzir os passos que a partir de agora nos propomos a seguir para a consecução de uma edição crítica do corpus poético atribuído a Luís de Camões. Dividimos há tempo 
esse nosso desejo angustiante com Marcia Arruda Franco e Sheila Moura Hue, de quem sempre recebemos apoio. Esperamos que, desde já, de forma disciplinada, ele possa apaziguar-se na medida mesma em que o trabalho propedêutico para a fatura de uma edição crítica seja levado a termo.

\section{(II)}

É possível produzir uma edição crítica seguindo-se à risca um dado método editorial? Apresentamo-nos essa mesma pergunta por vezes incontáveis e chegamos paulatinamente a resposta tateante que se segue.

As tentativas de regulação metódica do conhecimento, que poderiam dar um cunho de cientificidade à prática editorial, esbarram, no entanto, na ignorância de uma racionalidade específica do saber histórico, que é o próprio reconhecimento da historicidade das categorias metódicas. Faz-se preciso escrutinar o método lachmanniano para averiguar em que medida "os princípios do procedimento para assegurar a validade do conhecimento" (RÜSEN, 2007, p. 10) histórico/ filológico, nele, são válidos e aceitáveis. Há uma primeira questão a ser colocada logo ao início de nossa reflexão. Pode um método de investigação e de geração de conhecimento durar sem praticamente alterações por mais de um século? As categorias críticas, que são categorias históricas, que operacionalizam o método de Karl Lachmann, podem ter ainda validade incondicional na segunda década do século XXI? Não teriam, desse modo, uma validade transistórica, ao menos para os praticantes desse método? Os filólogos brasileiros, partidários do lachmannismo, dizem sim a essas questões. Mas não é de pasmar pensar que um método proposto pela primeira vez no século XIX, mesmo que consideremos o importante trabalho de sua revitalização proposto por Giorgio Pasquali, possa continuar a ser ajuizado pelos filólogos brasileiros como pertinente à edição de tradições textuais as mais variadas, edição essa balizada pelas categorias metódicas do lachmannismo romântico? Há razões ou não para o nosso pasmo? Os objetivos a que se visa com o método de Karl Lachmann, sumariados por Segismundo Spina, como sejam o restituir o texto à sua forma genuína, o deduzir do "texto aquilo que nele não está" (SPINA, 1994, p. 83), como "sua autoria, a biografia do autor, a datação do texto, a sua posição na produção literária do autor e da época, bem como a sua avaliação estética" (SPINA, 1994, p. 83), e, também, o tornar o texto um documento da Geistgeschichte, não são passíveis, hoje em dia, de consecução, não só a depender da tradição textual com que se labore, mas sobretudo a depender da visada historiográfica com que se aborde a tradição textual. Como já discutimos anteriormente em outros estudos, é historicamente pertinente falar sempre de 
recuperação filológica da "genuinidade" de um texto? ${ }^{1}$ É preciso ainda questionar como se pode determinar a autoria de um texto se não houvesse nele marcas supostamente autorais que permitissem ao filólogo estabelecer o elo genético entre texto e autor. Nesse sentido, não tem cabimento, segundo nosso juízo, dizer que a filologia deduz do "texto aquilo que nele não está", pois se não houvesse marcas, traços, a serem interpretados, não haveria como aplicar o procedimento do $u s u s$ scribendi ${ }^{2}$ e, muito menos, relacionar o texto a um certo estilo epocal revelador de uma dada sensibilidade, tais como os preconizam os praticantes do método de Karl Lachamnn. Se o método de Karl Lachmann, ao menos para os lachmannianos, é espécie de regra canônica de composição historiográfica visante aos fins acima especificados conforme Segismundo Spina, ele, na medida em que prescreve a aplicação de princípios metódicos, produz o necessário e correlato enfraquecimento de qualquer potencialidade crítica, pois essa se vê obstada pela própria rigidez dogmática. Jörn Rüsen, ao pensar na correlação entre métodos e operação historiográfica, assevera que: "Como a ciência é uma oportunidade institucionalizada de inovação, esquemas de ordenamento desse tipo teriam efeito contraproducente se assumissem a forma de modelos", o que implica fundar a criticidade na capacidade de romper com a modelização do procedimento interpretativo toda vez que esse se revele como obstáculo à inteligibilidade histórica do objeto sob análise. Todo esforço deve ser empreendido para que se possa proteger o pensamento filológico de uma concepção unitária de ciência, dependente, como no caso do método de Karl Lachmann, de uma racionalidade de tipo monológico.

1 Para uma crítica da busca pelo texto genuíno, ver MOREIRA, Marcello. Critica Textualis in Caelum Revocata? Uma proposta de edição e estudo da tradição de Gregório de Matos e Guerra. São Paulo: Edusp, 2011, sobretudo, a "Introdução" e o primeiro capítulo do "Speculum Minus", p. 73-163. Cabe ainda dizer, com brevidade, que desde Ranke a história é compreendida como fruto da conjunção da racionalidade metódica e da arte, expressa desse modo pelo historiador alemão: "A história distinguese das demais ciências por ser, simultaneamente, arte. Ela é ciência ao coletar, achar, investigar. Ela é arte ao dar forma ao colhido, ao conhecido e ao representá-los. Outras ciências satisfazem-se em mostrar o achado meramente como achado. Na história, opera a faculdade da reconstituição. Como ciência, ela é aparentada à filosofia; como arte, à poesia". A filologia, como ciência histórica, propôs-se, no século XIX, ser reconstitutiva, mas nunca se questionou a validade transistórica dessa reconstituição, evidente nas edições críticas lachmannianas produzidas até hoje entre nós, fruto de uma interpretação que era e é uma verdadeira operação cognitiva. A "genuinidade" era e é categoria central dessa cognição, mas sem que se questionasse ou reconhecesse sua historicidade. É sempre cabível falar do "genuíno" em termos ecdóticos? Reconstituiu-se ou se tentou reconstituir, a partir dela, tanto o corpus atribuído a Luís de Camões quanto aquele atribuído a Gregório de Matos e Guerra. Mas, se a filologia é "um modo especificamente histórico de constituir sentido acerca da experiência do tempo" (RÜSEN, 2007, p. 21), ela deveria partir da assunção da possibilidade da relativização histórica das categorias com que opera sua interpretação e cognição dos objetos, ou seja, deveria reconhecer a facticidade de fatos históricos, estando, por razões óbvias, neles subsumidas todas as categorias de pensamento.

2 Para a compreensão dos problemas ligados à operacionalização do procedimento do usus scribendi, ver MOREIRA, Marcello, 2011a; e, também, MOREIRA, Marcello. "Uma crítica a Spaggiari e Perugi”. In: . Tágides: Revista de Literatura, Cultura e Arte Portuguesas. São Paulo, 2011, v. 1, p. 113-131. 
A condição da escrita de uma crítica filológica historicamente pertinente é assegurar a consciência de uma diferença e distância entre nós mesmos e o passado, que pressupõe sempre o reconhecimento prévio de que nós mesmos somos históricos. Se se pode propor que o texto histórico e filológico “deve ser visto como um 'substituto' presente aqui e agora no lugar de um passado não presente" (ANKERSMIT, 2006, p. 95-114), essa substituição deve atender a determinadas condições de produção do saber histórico, pois esse passado não presente a ser apresentado textualmente a um leitorado contemporâneo pode dar uma ideia muito díspar das práticas letradas de que é parte a depender da historicização mais ou menos rigorosa das categorias que operacionalizarão sua produção. A historicização das categorias que operacionalizam a produção desse passado é determinante da representação do passado levada a efeito pelo historiador e pelo filólogo.

Por essa razão, propomo-nos, ao refletir sobre as condições históricas necessárias à fatura de uma edição crítica do corpus poético atribuído a Luís de Camões, o estabelecimento de procedimentos propedêuticos à edição propriamente dita:

1) Analisar a pertinência de categorias lachmannianas determinantes da feição de edições críticas, como "genuinidade" e "originalidade", para a fatura de uma edição do corpus poético atribuído a Luís de Camões.

2) Escrutinar, por razões óbvias, o que se entendia por "autoria" no mundo lusobrasileiro entre os séculos XVI e XVIII.

3) Verificar em que medida os conceitos de mouvance, formalizado por Paul Zumthor, e de variance, pensado pela primeira vez por Bernard Cerquiglini, têm pertinência quando relacionados às práticas letradas da monarquia portuguesa.

4) Estudar os critérios retóricos e bibliográficos que ordenaram as primeiras edições dos poemas atribuídos a Luís de Camões assim como a organização interna dos livros de mão subsistentes.

5) Analisar em que medida métodos como o lachmanniano estão aptos ou não a operacionalizar a fatura de edições críticas de corpora poéticos quinhentistas e seiscentistas.

6) Criticar os métodos editoriais vigentes a partir do sistemático entrecruzamento das tradições metódicas em crítica textual com o rico campo historiográfico do século XX.

7) Propor, se necessário, novos procedimentos de fatura de edição crítica para o corpus poético atribuído a Luís de Camões, caso os que existam não atendam a nossas necessidades de historicização das práticas letradas que doutrinam o fazer poético na monarquia lusa. 
8) Estudar de forma sistemática os chamados "acidentais" (accidentals) de impressos e livros de mão, para tentar estabelecer uma relação entre eles e a actio.

9) Tentar compreender as razões históricas para a proliferação de variantes textuais entre os séculos XVI e XVIII e verificar em que medida se pode relacioná-las à noção de erro, corruptela ou degradação ou ainda a fenômenos históricos determinantes de práticas letradas situadas em tempo e espaço específicos.

10) Estudar as práticas cortesãs de composição de repente ou em performance, valendo-nos de testemunhos não apenas luso-brasileiros mas também europeus, coetâneos daqueles.

11) Propor formas ótimas de edição, se necessário de tipo hipertextual, caso seja preciso apresentar todas as variantes ou versões de um mesmo poema, desde que o procedimento se justifique por razões históricas.

\section{REFERÊNCIAS:}

ANKERSMIT, Frank R. "Historicismo, Pós-Modernismo e Historiografia". In: MALERBA, Jurandir. A história escrita: teoria e história da historiografia. São Paulo: Contexto, 2006, p. 95-114.

CERQUIGLINI, Bernard. "Éloge de la Variante". In: Langages: ManuscritÉcriture et Production Linguistique, Paris, 69: 25-51, 1983.

CERQUIGLINI, Bernard. Éloge de la Variante: Histoire Critique de la Philologie. Paris: Éditions du Seuil, 1989.

MOREIRA, Marcello. Critica Textualis in Caelum Revocata? Uma proposta de edição e estudo da tradição de Gregório de Matos e Guerra. São Paulo: Edusp, 2011a. . "Uma crítica a Spaggiari e Perugi”. In: Tágides: Revista de Literatura, Cultura e Arte Portuguesas. São Paulo, 2011b, v. 1, p. 113-131.

PASQUALI, Giorgio. Storia dela Tradizione e Critica del Testo. Premessa di Dino Pieraccioni. Firenze: Le Lettere, 1988.

RÜSEN, Jörn. História viva: teoria da história III - Formas e funções do conhecimento histórico. Brasília: Editora UnB, 2007.

SPINA, Segismundo. Introdução à edótica: crítica textual. São Paulo: Ars Poetica/ Edusp, 1994.

ZUMTHOR, Paul. Essai de Poétique Médiévale. Paris: Édtions du Seuil, 1972. 


\section{MINICURRÍCULO:}

Professor titular de Letras luso-brasileiras (séculos XVI, XVII e XVIII) e de Historiografia e História Literária do Departamento de Estudos Linguísticos e Literários da Universidade Estadual do Sudoeste da Bahia. É autor de Critica Textualis in Caelum Revocata? Uma proposta de edição e estudo da tradição de Gregório de Matos e Guerra (EDUSP, 2011). Organizou os dossiês Brasil Colônia (Revista USP, 2006, com Luciana Gama), Nova Filologia (Tágides, 2011, com Marcia Arruda Franco), O romance no século XIX (Floema, 2011, com Márcia Abreu). 